\title{
PERCEPÇÃO AMBIENTAL POR MEIO DA FOTOGRAFIA: FERRAMENTA DE EDUCAÇÃO AMBIENTAL PARA ALÉM DOS MUROS DA ESCOLA
}

Renato Fernando Menegazzo ${ }^{1}$

Resumo: Educação Ambiental são os processos por meio dos quais são construídos valores sociais, conhecimentos, habilidades, atitudes e competências voltados à conservação do meio ambiente. $O$ presente trabalho objetivou a utilização da percepção ambiental como instrumento de Educação Ambiental no âmbito escolar, por meio da fotografia e de questionário semiestruturado. Os alunos, que praticamente consideravam meio ambiente sinônimo de natureza, passaram a vê-lo de forma mais abrangente e condizente com a definição da Conferência de Estocolmo. Conclusão: a Educação Ambiental pode interferir na realidade mediante um trabalho contínuo e permanente na escola, de modo a ultrapassar seus muros e atingir a sociedade.

Palavras-chave: Educação Ambiental; Sensibilização; Mudança Social.

${ }^{1}$ Instituto Federal de Educação, Ciência e Tecnologia de Rondônia. E-mail: renato.menegazzo@ifro.edu.br Revbea, São Paulo, V. 13, No 4: 298-312, 2018. 


\section{Introdução}

Educação Ambiental são os processos por meio dos quais o indivíduo e a coletividade constroem valores sociais, conhecimentos, habilidades, atitudes e competências voltadas para a conservação do meio ambiente, bem como de uso comum do povo, essencial à sadia qualidade de vida e sua sustentabilidade (BRASIL, 1999). Também é definida como uma dimensão da educação, uma atividade intencional da prática social, que deve imprimir ao desenvolvimento individual um caráter social em sua relação com a natureza e com os outros seres humanos, visando potencializar essa atividade humana com a finalidade de torná-la plena de prática social e de ética ambiental (BRASIL, 2012).

A Educação Ambiental é resultado de discussões travadas em meados de 1965, na Conferência em Educação na Universidade de Keele, na GrãBretanha. Na ocasião, foi aceito que a Educação Ambiental deveria se tornar uma parte essencial da educação de todos os cidadãos e seria vista como sendo essencialmente conservação ou ecologia aplicada (DIAS, 2004). Hoje, porém, entende-se a Educação Ambiental como um processo coletivo que leva os cidadãos a pensar, conhecer, fazer e ser conscientes de seus direitos e responsabilidades, favorece o diálogo como forma de se chegar a objetivos desejados, contempla alternativas sociais e naturais que beneficiam a grande maioria das pessoas e integra o ser humano ao meio em que vive (REIGOTA, 1995; TALAMONI, 2003).

Autores como Pelicioni e Philippi Jr. (2005) entendem que por meio da Educação Ambiental, cidadãos podem ser formados e preparados para a reflexão crítica e para uma ação social corretiva ou transformadora do sistema, de forma a tornar viável o desenvolvimento integral dos seres humanos. Para isso, segundo eles, deve ser levado em consideração que a sociedade capitalista urbano-industrial e seu atual modelo de desenvolvimento econômico e tecnológico têm causado crescente impacto sobre o ambiente e a sociedade.

É fato que a preocupação com o meio ambiente tomou peso a partir das últimas décadas, devido à degradação ambiental provocada pelo atual modelo de desenvolvimento urbano: desprovido de planejamento e manejo adequado dos recursos naturais. Por isso, busca-se proporcionar, por meio da Educação Ambiental, a construção de conhecimentos, o desenvolvimento de habilidades, atitudes e valores sociais, o cuidado, a justiça, a equidade socioambiental e a proteção do meio ambiente natural e construído (BRASIL, 2012).

É importante que os indivíduos e a comunidade tomem consciência do seu meio ambiente e adquiram conhecimentos, valores, habilidades, experiências e determinação, para se tornarem aptos a agir e resolver problemas ambientais, presentes e futuros (DIAS, 2004). Essa tomada de consciência pode ser fomentada pelo estudo da percepção ambiental. Estudo este fundamental para que se possa compreender melhor as inter-relações entre o homem e o ambiente. Saber como os indivíduos percebem o ambiente em que vivem, suas fontes de satisfação e insatisfação, é de fundamental

revista brasileira educação ambiental 
importância, pois só assim, conhecendo a cada um, será possível a realização de um trabalho com bases locais, partindo da realidade do público (FAGGIONATO, 2002).

Durkheim (2009) define a percepção como um modo de representação social. Faggionato (2002) acrescenta. Para a autora, trata-se de um conceito permeável entre Biologia, Geografia e Psicologia, inerente a cada ser humano, que percebe, reage e responde de forma diferente tanto às relações interpessoais quanto às ações sobre o meio. Margeando a percepção ambiental, encontra-se a cultura local, história, classe social, ambientes rotineiros e constituição familiar e religiosa que causam uma infinidade de possíveis perfis de observação e percepção (RODRIGUES et al., 2012).

Pelo exposto acima, propõe-se que o tema meio ambiente seja trabalhado com a finalidade de se proporcionar aos alunos uma diversidade de experiências e ensinar-Ihes formas de participação para que possam ampliar sua consciência sobre questões relativas ao mesmo e, assim, assumir de forma independente e autônoma, atitudes e valores voltados para a sua proteção e melhoria (ALVES; LIMA, 2011). Para isto, conforme os autores, torna-se primordial a busca de alternativas educacionais que propiciem aos educandos o desenvolvimento de uma percepção abrangente da questão ambiental, proporcionando-Ihes a compreensão das inter-relações entre os diferentes aspectos que envolvem a realidade.

Sob um enfoque holístico, o ensino sobre o meio ambiente deve contribuir principalmente para o exercício da cidadania, estimulando a ação transformadora, além de buscar aprofundar os conhecimentos sobre as questões ambientais, estimular a mudança de comportamento e a construção de novos valores. Porém, a conscientização dos alunos em relação ao tema só será possível através da prática efetiva, da ação de educandos e professores, que os levarão a reconhecerem-se como cidadãos capazes de compreender que o meio ambiente necessita de proteção e preservação (ALVES; LIMA, 2011).

\section{Metodologia}

Diversas são as formas de se estudar a percepção ambiental: questionários, mapas mentais ou contorno, representação fotográfica, etc. Durante a execução do presente trabalho, realizou-se atividades de percepção ambiental por meio da fotografia, no período compreendido entre outubro e dezembro de 2016 e fevereiro de 2017. Tais atividades foram organizadas e supervisionadas por acadêmicos do curso de Licenciatura em Ciências Biológicas, do Instituto Federal de Educação, Ciência e Tecnologia de Rondônia, campus Colorado do Oeste, que integram o Programa Institucional de Bolsa de Iniciação à Docência (PIBID), junto a alunos de escolas estaduais de ensino fundamental e médio de municípios que fazem parte da região Cone Sul de Rondônia. 
O trabalho abrangeu estudantes de $6^{\circ}$ e $9^{\circ}$ anos do Ensino Fundamental e $1^{\circ}$ e $3^{\circ}$ anos do Ensino Médio, de escolas das redes estadual e particular de ensino, localizadas nos municípios de Cerejeiras e Colorado do Oeste. A escolha das séries foi baseada nos estudos de Bezerra et al. (2014), segundo os quais é a partir do $6^{\circ}$ ano que a criança expande seu conhecimento geográfico e passa a ser capaz de atribuir significado aos objetos do meio. Ao todo, participaram do projeto 179 alunos, sendo 90 de Colorado do Oeste (46 feminino e 44 masculino) e 89 de Cerejeiras (44 feminino e 45 masculino), conforme pode ser observado no gráfico abaixo (Figura 1).

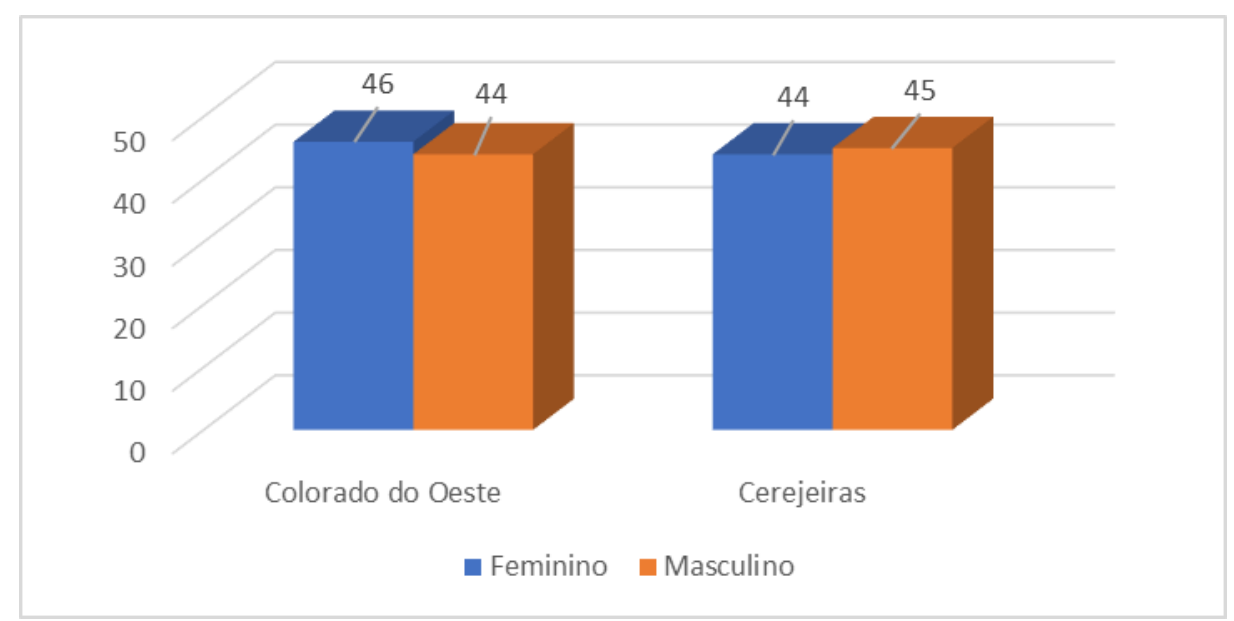

Figura 1: Quantitativo de alunos participantes do projeto, por sexo.

Por faixa etária, trabalharam a percepção ambiental 64 alunos de Colorado do Oeste de 10 a 12 anos; 23 de Colorado do Oeste e 49 de Cerejeiras, de 13 a 15 anos; 3 de Colorado do Oeste e 40 de Cerejeiras, de 16 a 18 anos (Figura 2).

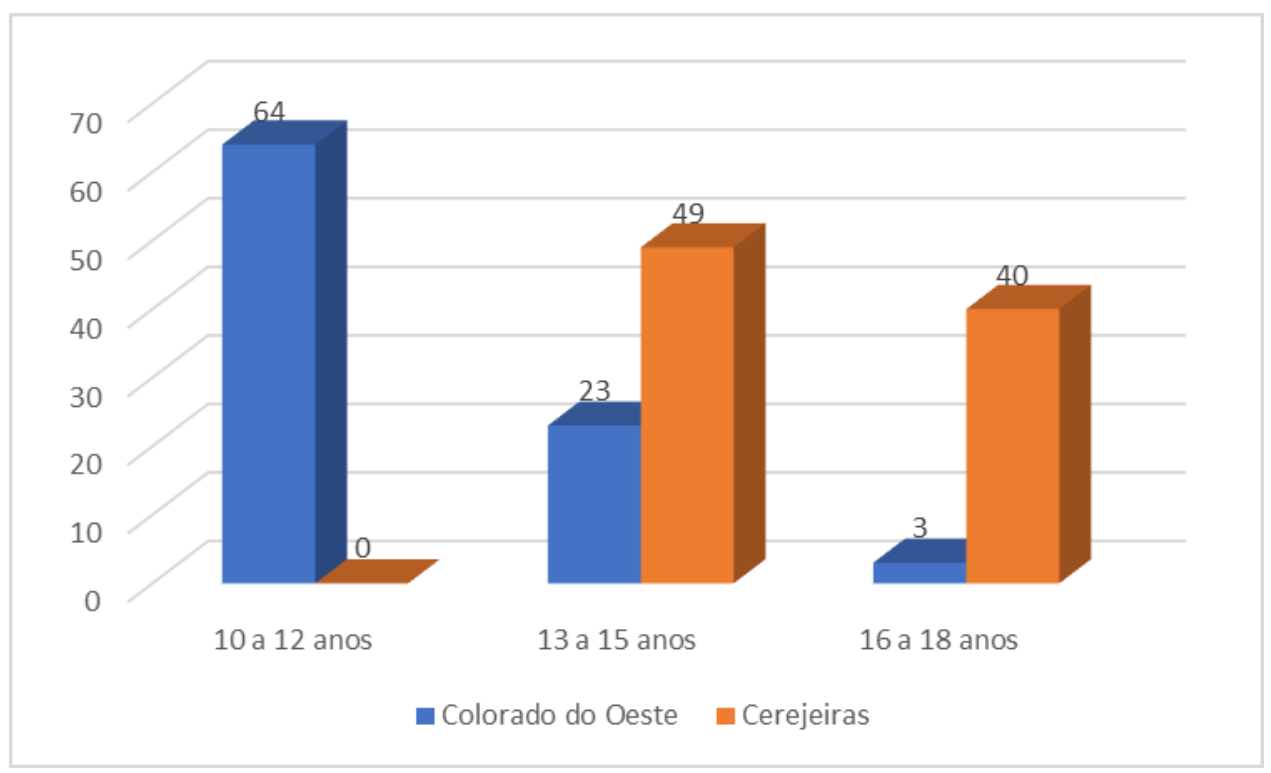

Figura 2: Faixa etária dos estudantes participantes de projeto.

Revbea, São Paulo, V. 13, № 4: 298-312, 2018. 
Para a realização da pesquisa, foi aplicado o modelo circular, no qual o problema de pesquisa é definido à luz de um paradigma teórico e, a partir de então, questões, que podem assumir a condição de hipóteses, são formuladas. Neste modelo, a coleta de informações é planejada e o pesquisador define o local do estudo e as estratégias de pesquisa. As etapas seguintes compreendem trabalhos de campo, análises das informações obtidas e a redação do relatório de pesquisa. Os dados são obtidos após cada trabalho de campo e orientam o pesquisador para os rumos que o levantamento irá tomar (ALENCAR, 2004).

O trabalho de campo foi qualitativo. Optou-se por este tipo de trabalho porque ele não se foca na representatividade numérica, mas sim na compreensão de um grupo social com intenção de explicar o porquê das coisas (GERHADT; SILVEIRA, 2009) e pode ser realizado de maneira direta ou indireta (GIL, 2002). Para o levantamento indireto da percepção ambiental, foi utilizada a fotografia para flagrar o meio ambiente. Trata-se de uma importante técnica pedagógica que pode ser utilizada pelos educadores para desenvolver conhecimento, compreensão, habilidades e motivação (MATTOS, MENEGAZZO; PILATI, 2008), além do espaço formal de ensino, podendo trazer motivação e empenho educacional.

A fotografia é uma experimentação interessante enquanto recurso comunicativo por ser sensível a nuances de cores, texturas e formas que as palavras ou outras formas de comunicação não expressam. Oferece as(os) educandas(os) maneiras mais lúdicas e poéticas de expressão e construção do conhecimento. As(os) educadoras(es) ambientais, enquanto mediadoras(es) do processo educacional, independentemente do modo escolhido para trabalhar a fotografia, desempenharão o papel de interpretar os sentidos e as percepções do sujeito (CARVALHO; GRUM, 2005).

Sob a supervisão de acadêmicos do curso de Licenciatura em Ciências Biológicas do IFRO, campus Colorado do Oeste, estudantes das redes estadual e particular de ensino efetuaram o registro fotográfico do ambiente em que estavam situados. Antes, porém, houve um trabalho de sensibilização em relação ao tema, para engajá-los em todas as atividades previstas para 0 projeto. Pessoas engajadas apresentam um desempenho melhor, uma atitude pró-social que as fazem aceitar mais frequentemente tarefas desafiadoras que exigem dedicação extra, ficam mais satisfeitas com suas atividades e experimentam com mais facilidade a sensação do flow, um estado em que você fica totalmente imerso no seu trabalho e que, posteriormente, é percebido como um período prazeroso (SCHAUFELI et al., 2012, apud SILVA, 2012).

Os trabalhos de registro fotográfico e sensibilização foram efetuados em quatro etapas: 1. mobilização e organização dos alunos para motivá-los a participar do projeto; 2. organização dos alunos em grupos de até dez integrantes para execução dos registros fotográficos de 10 imagens por grupo, retratando seus respectivos entendimentos sobre o que é meio ambiente e montagem de slides com as fotos, para apresentação em sala de aula; 3. intervenção didático-pedagógica sobre conceitos de meio ambiente, diferentes Revbea, São Paulo, V. 13, № 4: 298-312, 2018. 
tipos de ambiente e estudos sobre como cada um percebe o ambiente em que está inserido, após as apresentações; e 4. novos registros fotográficos e comparação com as fotos tiradas antes da intervenção didático-pedagógica, para aferir a evolução do entendimento sobre o assunto.

Para o levantamento direto da percepção ambiental, foi aplicado um questionário semiestruturado, com questões abertas e fechadas, ou seja, foi empregada uma técnica de investigação composta por um número mais ou menos elevado de questões apresentadas por escrito às pessoas, tendo por objetivo o conhecimento de opiniões, crenças, sentimentos, interesses, expectativas, situações vivenciadas, etc. (GIL, 1999). Ou, conforme atestam Chaer, Diniz e Ribeiro (2011), uma técnica que serve para coletar as informações da realidade.

Ferramenta para a realização de um trabalho quantitativo de levantamento de dados, o questionário foi proposto por Freitas (2009), dentro do Programa de Pós-Graduação em Ciências Florestais, da Universidade Federal de Lavras, Departamento de Ciências Florestais, com adaptações. Trata-se do questionário misto, Survey, intitulado "Percepção Ambiental: Pesquisa do perfil do aluno do Curso de Pós-Graduação em Manejo Ambiental de Sistemas Agrícolas".

Entende-se que juntos, registros fotográficos - trabalho qualitativo - e questionário - trabalho quantitativo -, possibilitam a compreensão de como as pessoas se sensibilizam, ou percebem o ambiente, e identificam as representações sociais que as mesmas apresentam sobre o tema. Com isso, dá-se um passo para se propor discussões pertinentes sobre a questão ambiental visando a desconstrução de representações sociais equivocadas e reforçar as representações coerentes, propiciando o desenvolvimento de conceitos e ações que conduzam ao pensamento da complexidade e conservação ambiental (FREITAS, 2009).

\section{Resultados e discussão}

Nas escolas em que o projeto foi executado, em Cerejeiras, foram organizados, ao todo, 10 grupos e obtidos 100 registros fotográficos no momento pré-intervenção didático-pedagógica e outros 100 no momento pósintervenção didático-pedagógica, totalizando 200 fotografias. Em Colorado do Oeste, foram organizados 15 grupos e obtidos mais 150 registros fotográficos no momento pré e outros 150 no pós didático-pedagógico, totalizando 300 fotografias.

Em todos os grupos, na primeira etapa, predominou o registro fotográfico de paisagens rurais, matas e pés de árvores, indicando uma percepção de que o meio ambiente é apenas paisagem natural, na qual o ser humano não está incluído, conforme pode ser observado nas imagens abaixo (Figuras 3 e 4). Também foram registradas imagens de plantações de soja e de pastagens, pelo fato de grande parte dos alunos participantes do projeto residirem na zona rural dos municípios.

revista brasileira educação ambiental 

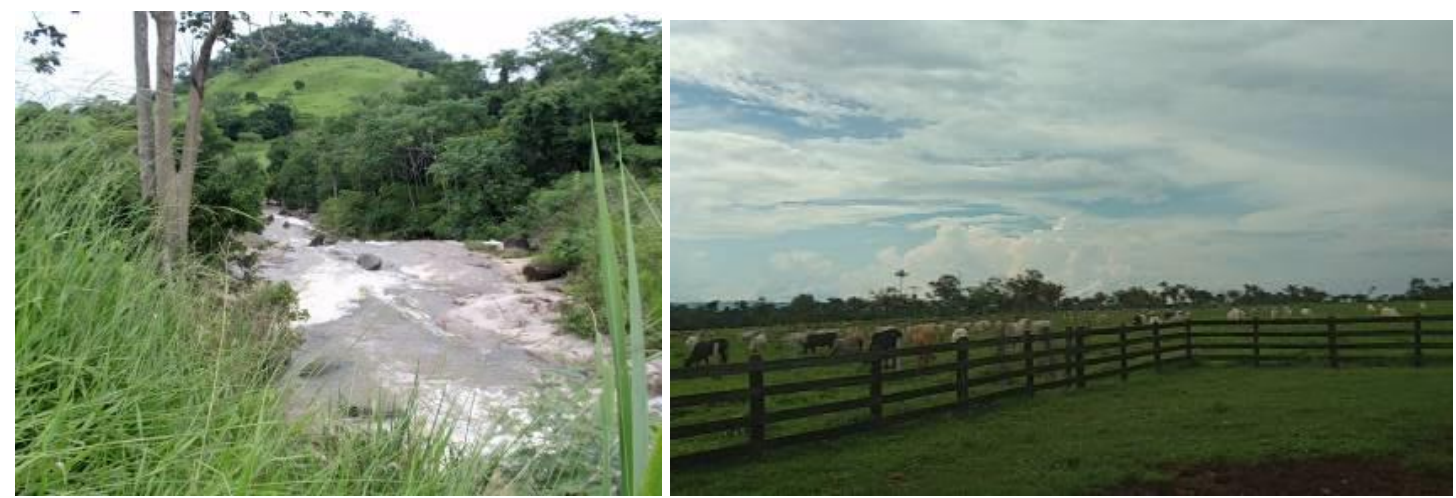

Figuras 3 e 4: Imagens de área natural e de pastagem, capturadas em Cerejeiras e Colorado do Oeste, demonstrando a visão de estudantes sobre o que consideravam meio ambiente.

A Figura 5, abaixo, também mostra a percepção inicial que estudantes tinham do que é meio ambiente. Ela foi apresentada por grupo do 9o Ano do Ensino Fundamental, composto por alunos residentes na zona rural de Colorado do Oeste. Nela, está registrada uma área parcialmente desmatada para ser utilizada na bovinocultura de corte, tal como aconteceu com muitas outras áreas também localizadas na região do Cone Sul do estado de Rondônia, da qual Colorado do Oeste faz parte. A imagem mostra um descampado seguido de um remanescente de floresta localizado na região chacareira do referido município.

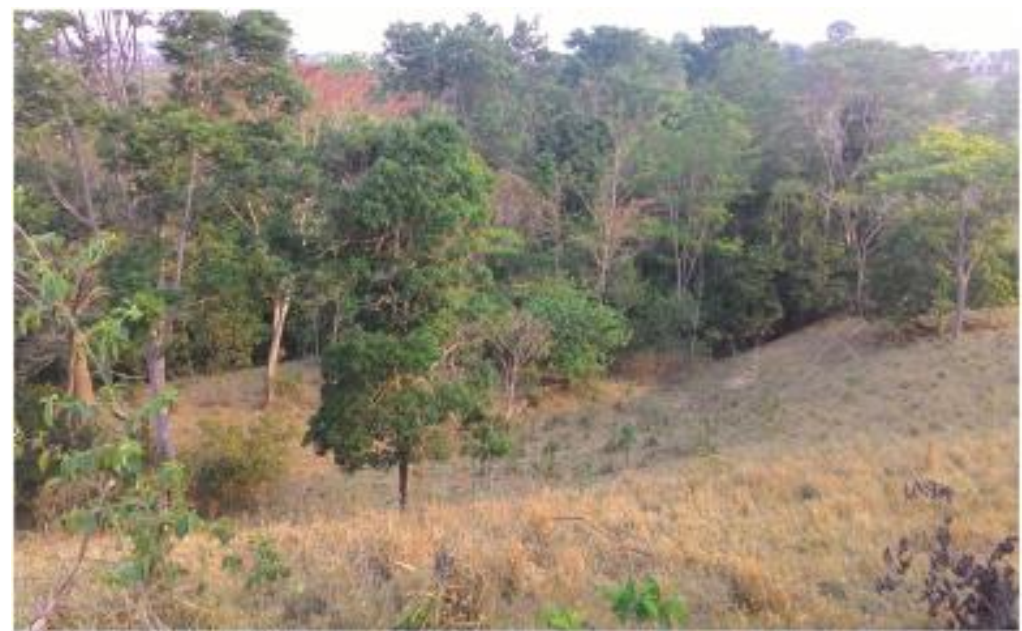

Figura 5: Área chacareira de Colorado do Oeste parcialmente desmatada para utilização na bovinocultura de corte.

$\mathrm{Na}$ segunda etapa do projeto, para associar o que a imagem trazia aos elementos ambientais que os alunos enxergavam na mesma e as sensações que isto produzia neles, a fim de se efetivamente obter suas percepções em relação ao ambiente registrado, foram apresentadas aos estudantes, durante intervenção didático-pedagógica, por meio de questionário semiestruturado, alternativas que os auxiliassem a expressar suas impressões sobre a 
fotografia. Os resultados desta percepção podem ser visualizados na Figura 6, abaixo.

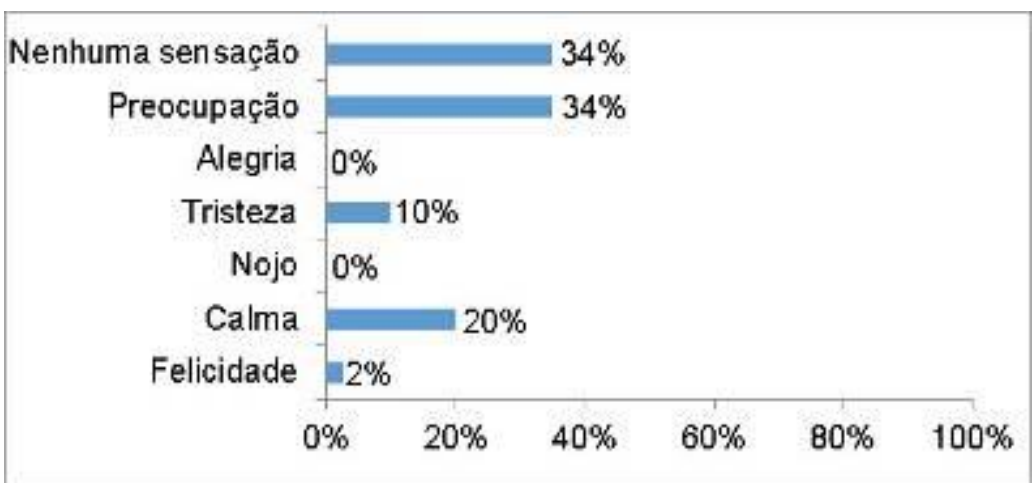

Figura 6: Percepção de sensações geradas nos alunos a partir da observação dos elementos ambientais registrados na Figura 5.

Os resultados demonstrados na Figura 6 apresentaram duas situações principais: uma, de "preocupação", em razão dos danos provocados ao meio ambiente pelo desmatamento, e a outra, de "nenhuma sensação", que demonstra uma precária percepção ambiental por parte do grupo estudado, ou de profunda apatia e indiferença em relação ao ambiente, possivelmente devido ao contato rotineiro com áreas como a trazida na fotografia. Ambos os grupos representaram 34\% dos entrevistados, somando $68 \%$ do total. Sensações de "calma", "tristeza" e "felicidade" foram assinaladas pelos $32 \%$ restantes. Os entrevistados ainda tinham as opções de assinalar "alegria" e "nojo".

As diferentes percepções estão em conformidade com Machado (1999), o qual assevera que a visão condiciona a sobrevivência dos seres vivos e é o principal fator que condiciona a percepção ambiental. Conforme o autor, a partir de observação, diversas sensações podem ser produzidas pelo sistema nervoso. O que é considerado bonito manifesta uma sensação agradável. Em oposição, o que é feio ou esquisito resulta em sensação de desconforto, que pode ser identificada como tristeza, preocupação e até mesmo nojo.

Ainda sobre a figura 5, que implicitamente demonstra uma interação entre o homem e o meio ambiente, a opinião dos estudantes revelou uma visão que transcende as fronteiras disciplinares e conceituais e eclode na consideração de que para estudar essa interação, é necessário considerar que a percepção vem sempre acompanhada da atribuição de valores e tomada de posições (como, por exemplo, o que é degradação para um, é sinal de progresso e qualidade de vida para outro, por gerar renda) e, portanto, deve ser analisada tanto do ponto de vista cognitivo como do afetivo (MACHADO, 1999).

$\mathrm{Na}$ terceira etapa, os alunos voltaram a efetuar registros fotográficos. Desta vez, passaram a registrar suas escolas, casas, jardins, ruas e outras áreas em que ocorreu ação antrópica, denotando mudanças nas suas percepções ambientais, inclusive, inserindo-se no meio por compreender que 
meio ambiente é qualquer lugar onde o indivíduo está presente, diferenciandose apenas sua classificação: artificial, natural e cultural. É o que demonstram as imagens abaixo (Figuras 7, 8 e 9), de plantas cultivadas no quintal da residência, de área pública com resíduos sólidos poluindo o local e de uma residência em meio a uma área modificada pela ação humana.
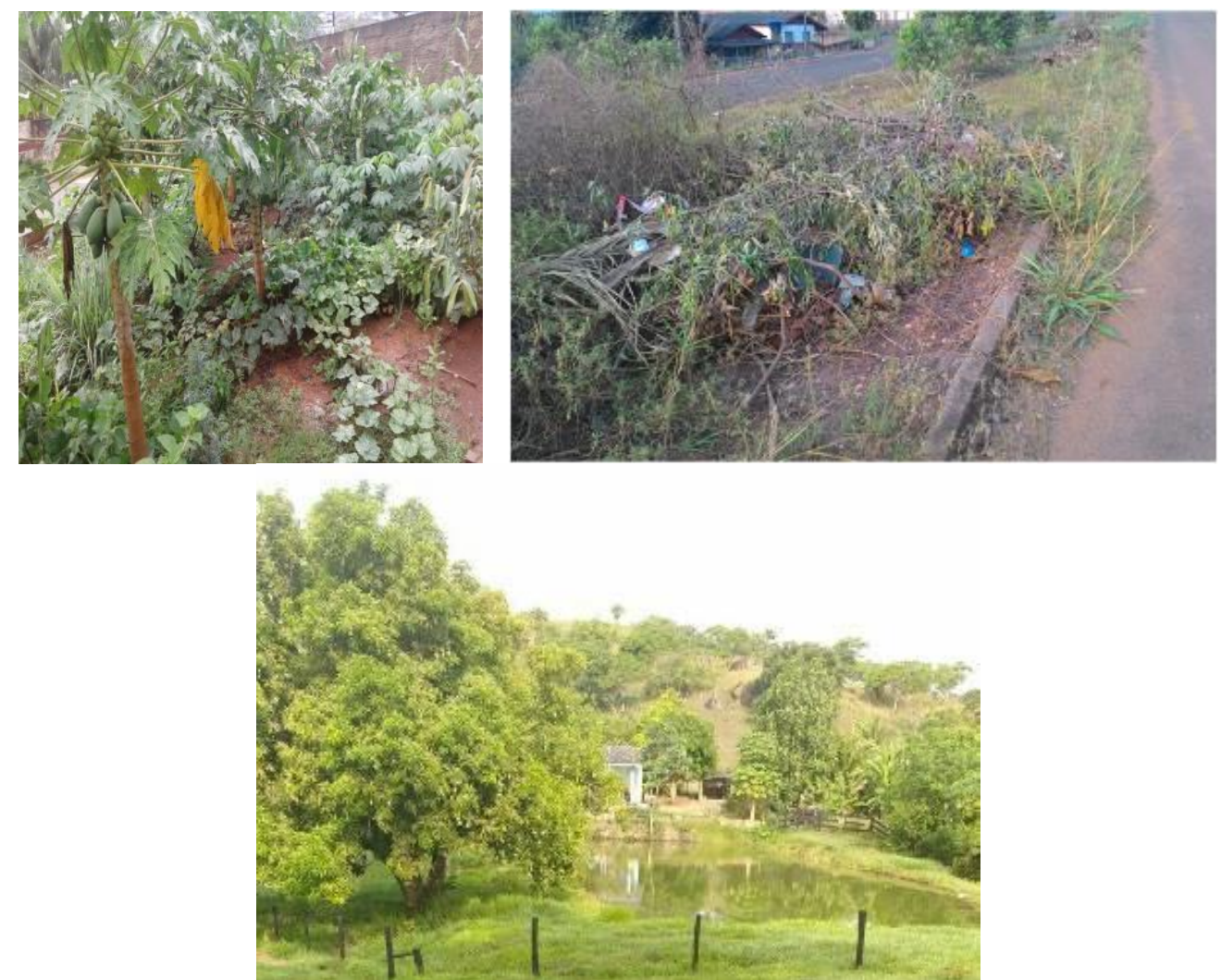

Figuras 7, 8 e 9: Imagens demonstrando a mudança de entendimento sobre o que é ambiente.

Analisando-se a percepção ambiental dos estudantes, uma das questões se caracteriza por ser estruturada e por solicitar ao respondente que assinalasse quais problemas ambientais mereceriam atenção e soluções mais urgentes. Para tratamento dos dados, os problemas apresentados foram agrupados em cinco classes: 1. "problemas atmosféricos", englobando poluição atmosférica, efeito estufa, redução da camada de ozônio e mudanças climáticas; 2. "problemas hídricos", reunindo poluição hídrica e escassez de água; 3. "problemas referentes à biodiversidade", concentrando perda da biodiversidade e diminuição de florestas; 4. "problemas referentes aos solos", concentrando degradação dos solos e desertificação; e 5. "problemas sociais", reunindo demasiado crescimento populacional e pobreza. Os resultados são expressos nos gráficos abaixo (Figuras 10 e 11). 


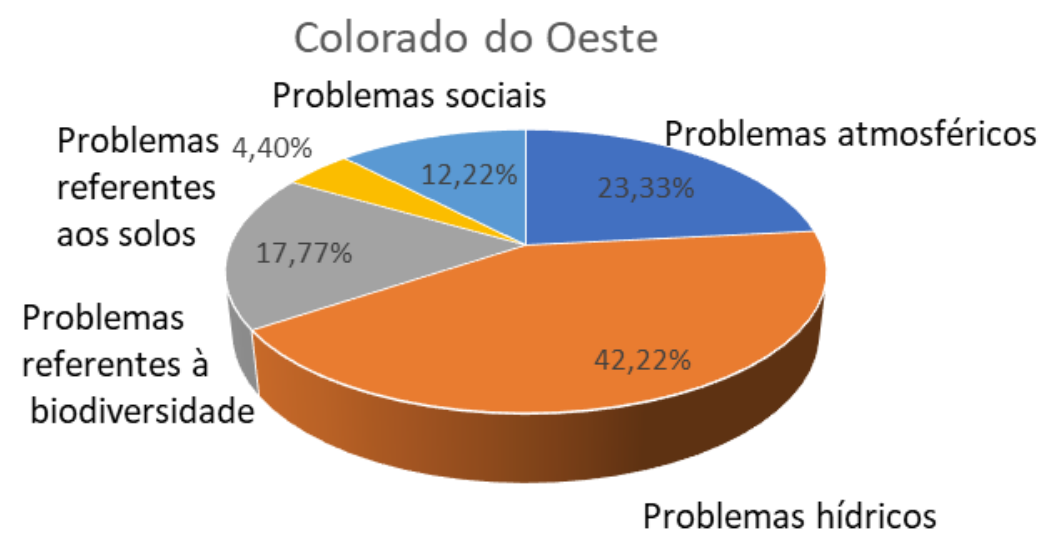

Figura 10: Problemas ambientais em Colorado do Oeste que mereceriam atenção e soluções de modo urgente.

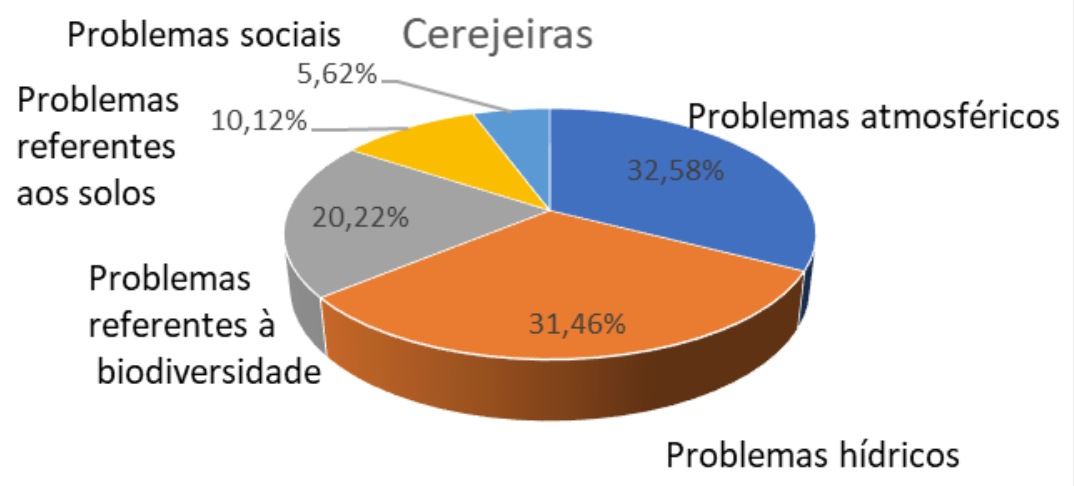

Figura 11: Problemas ambientais em Cerejeiras que mereceriam atenção e soluções de modo urgente.

Analisando-se os gráficos, fica evidente que a maioria dos estudantes, tanto de Cerejeiras como de Colorado do Oeste, consideram que o problema que mais merece atenção e solução está relacionado aos recursos hídricos, seguido dos problemas atmosféricos, dos relacionados à biodiversidade, aos relativos aos solos e, por fim, aos sociais. Embora todos os problemas estejam interligados, com um agravando o outro e vice-versa, o fato de a preocupação com os recursos hídricos ocupar o topo dentre as questões que merecem maior atenção não é mera coincidência. Há muito e por diferentes meios a população em geral têm sido alertada sobre a escassez de água no mundo, tanto para as pessoas beber, satisfazer suas necessidades higiênicas e produzir alimentos. Por isso, os estudantes também responderam que a escassez de água é, dentre os problemas ambientais, o que mais lhes chama a atenção, conforme pode ser observado no gráfico abaixo (Figura 12). 


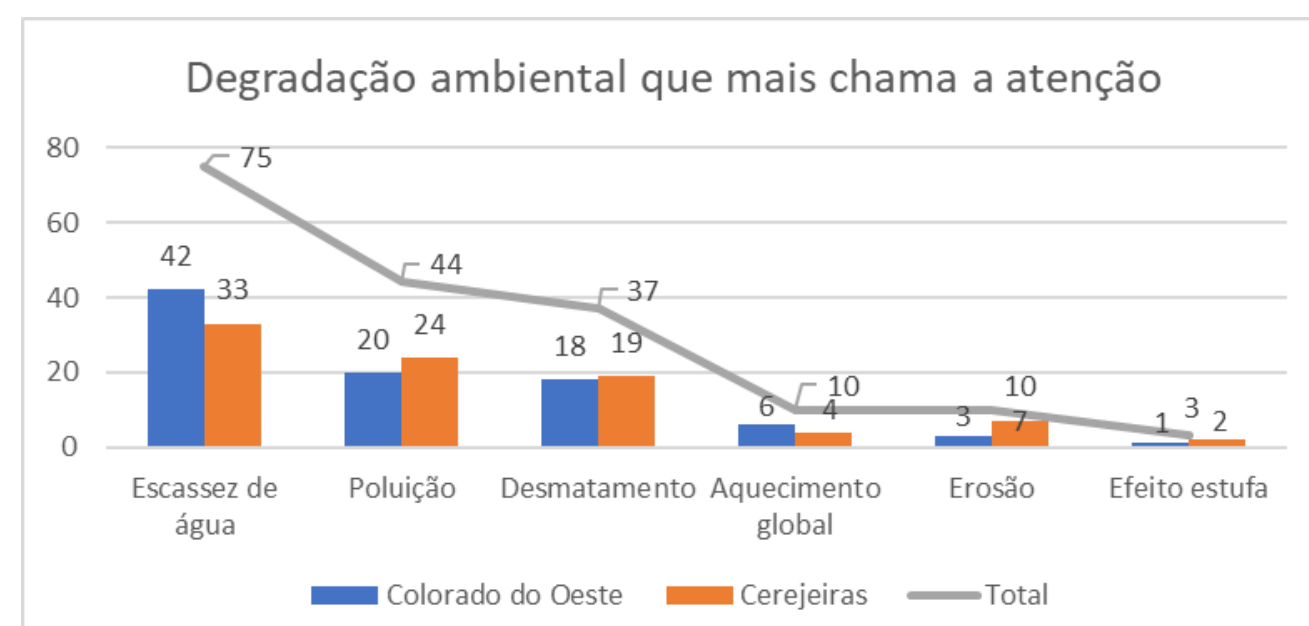

Figura 12: Escassez de água destaca-se dentre os problemas apontados pelos alunos.

Questões relativas ao acesso regular à água potável e segura têm causado preocupação, principalmente em países em desenvolvimento, que sofrem com a rápida expansão urbana, o adensamento populacional e a ocupação de áreas periurbanas e rurais, com evidentes deficiências e dificuldades no suprimento de água para satisfazer às necessidades básicas diárias. O provimento adequado de água, em quantidade e qualidade, é essencial para o desenvolvimento socioeconômico local, com reflexos diretos sobre as condições de saúde e de bem-estar da população (RAZZOLINI; GÜNTHER, 2008) e os estudantes têm a percepção desta realidade.

A Educação Ambiental prepara as gerações de seu país, tornando-o instruído em termos de meio ambiente e, portanto, dotando-o de mais oportunidades para ser bem-sucedido em seu desenvolvimento. Os respondentes demonstraram ter a percepção deste fato, assinalando no questionário uma ou mais ações das quais estariam dispostos a participar para mitigar os problemas ambientais atuais, a exemplo de separar o lixo para ser reciclado, diminuir o desperdício de água, deixar de consumir produtos advindos de processos poluidores do meio ambiente, campanha contra empresas poluidoras, pagar mais impostos para promover a conservação ambiental e contribuir financeiramente com organizações ambientais, conforme pode ser observado no gráfico a seguir (Figura 13). 


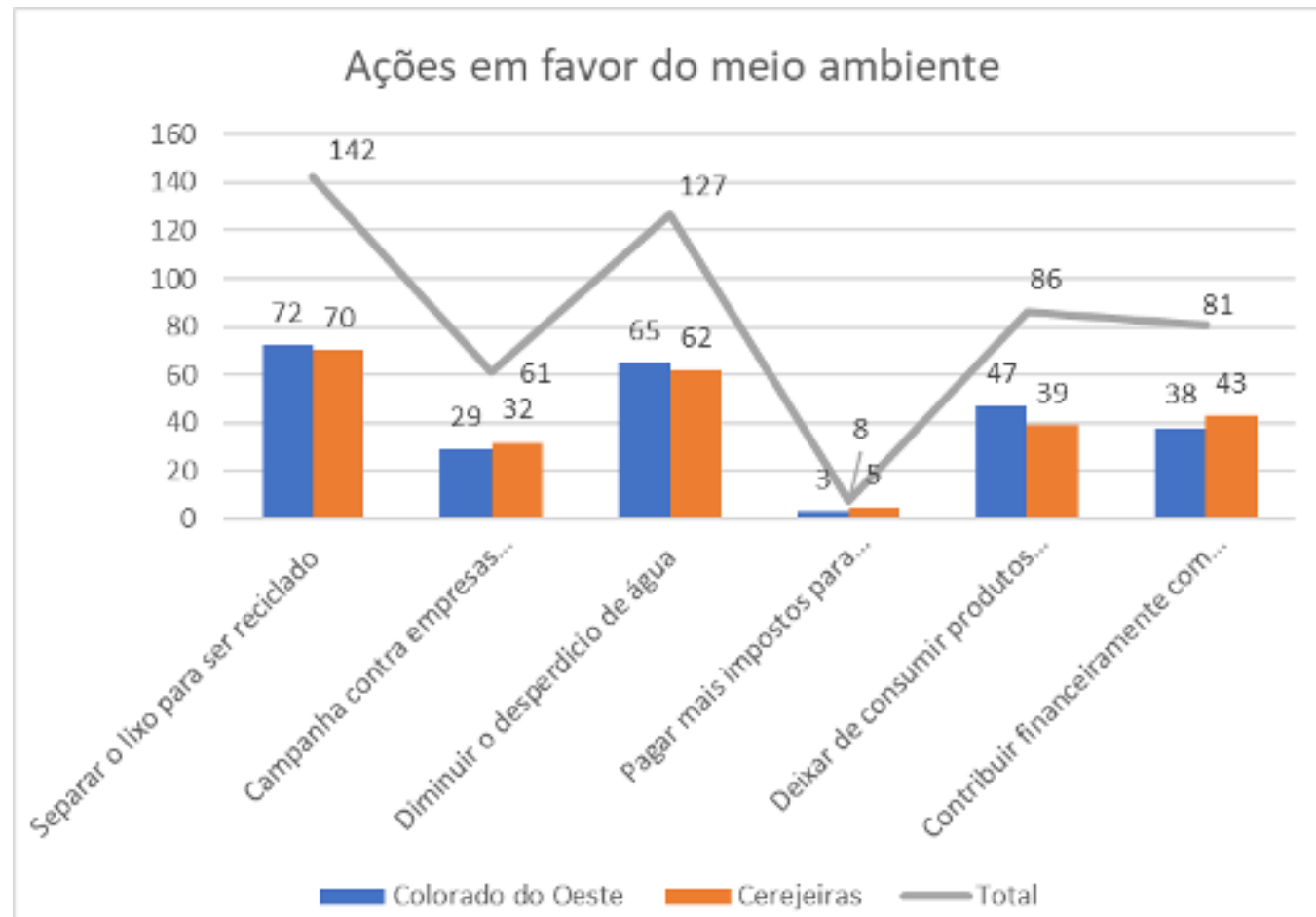

Figura 13: Ações que os alunos ajudariam a realizar para mitigar os problemas ambientais.

Onde o significado do meio ambiente não for atribuído adequadamente, o desenvolvimento fracassará. E como realizar isso? Através da comunidade. Ela deve agir para cuidar do seu próprio meio ambiente. Os cuidados com o planeta Terra e a vida sustentável podem depender das conviç̧ões das pessoas e de seu compromisso para com tais convicções, mas é através da própria comunidade que a maioria das pessoas pode melhor expressar esse compromisso (MACHADO, 1999).

A degradação ambiental decorre, dentre outros aspectos, da forma como percebemos o meio ambiente. A ausência, inadequação ou escassez do conhecimento gera ações que em geral, estão em desacordo com as leis naturais. Quanto mais aprendemos, entendemos a realidade em que vivemos, mais comprometidos e solidários tornamo-nos. Por isso, a Educação Ambiental no âmbito da escola pode interferir na atual realidade, porque atinge os alunos e os demais segmentos da sociedade, já que a inserção da dimensão ambiental na escola proporciona a realização de um trabalho contínuo e permanente e as transformações alcançadas, transpõem os muros da mesma (SILVA, 1995, apud SILVA; LEITE, 2008). 


\section{Considerações finais}

O projeto demonstrou a necessidade de se estimular sentimento de afinidade e mutualismo entre estudantes e o local onde vivem, para despertar ou potencializar o sentimento de pertencimento ao local, indo além do enfoque de áreas degradadas e questões sociais que lhes dizem respeito.

Com os registros fotográficos e as intervenções didático-pedagógicas, exemplificou-se como cada indivíduo possui percepções diversas sobre um mesmo objeto e ambiente e os estudantes se descobriram como parte das áreas urbanas e rurais, nascentes, corpos hídricos, acidentes geográficos e perfis de solo da região em que estão inseridos.

Com o trabalho, buscou-se despertar o desejo de reduzir os problemas e impactos ao ambiente. Não há outro caminho. Só se cuida daquilo que se conhece, gosta e valoriza, porque, como elo de uma grande corrente, descobre-se que as ações que cada um realiza terão repercussão e atingirão positiva ou negativamente tanto aos outros como a si próprio.

A ação antrópica é necessária, mas precisa acontecer com ética e racionalidade. Cada elemento de um sistema social e/ou natural deve ser respeitado, porque é insubstituível na manutenção da harmonia. Porém, isto somente se tornará realidade com a formação de sujeitos ecológicos estudiosos da casa onde vivem -, potencialmente protetores do ambiente.

Por tudo isso, entende-se que a Educação Ambiental no âmbito da escola pode interferir na atual realidade mediante um trabalho contínuo e permanente, capaz de atingir a sociedade, porque as transformações que proporciona têm potencial de ultrapassar seus muros.

\section{Referências}

ABREU, D. G.; CAMPOS, M. L. A. M.; AGUILAR, M. B. R. Educação Ambiental nas escolas da região de Ribeirão Preto (SP): concepções orientadoras da prática docente e reflexões sobre a formação inicial de professores de química. Química Nova, São Paulo, n. 3, v. 31, p. 688-693, 2008.

ALENCAR, E. Metodologia científica e elaboração de monografia. Lavras: UFLA/FAEPE, 2004.

ALVES, L. R. F.; LIMA, T. R. A dimensão da percepção ambiental no ensino do município de Paracatu - MG. In: II Simpósio de Educação Ambiental e Transdisciplinaridade. Anais... Goiânia: Universidade Federal de Goiás, 2011. Disponível em: <https://nupeat.iesa.ufg.br/up/52/o/10.Percep o ambiental.pdf>. Acesso em: 29 ago. 2016.

BEZERRA, Y. B. S.; PEREIRA, F. S. P.; SILVA, A. K. P.; MENDES, D. G. P. S. Análise da percepção ambiental de estudantes do ensino fundamental II em uma escola do município de Serra Talhada (PE). Revista Brasileira de Educação Ambiental. São Paulo, v. 9, n. 2, p. 472-488, 2014. 
BRASIL. Lei Federal № 9.795, de 27 de abril de 1999. Dispõe sobre a Educação Ambiental, institui a Política Nacional de Educação Ambiental e dá outras providências. Diário Oficial da União, Brasília, 28 abr. 1999.

BRASIL. Ministério da Educação. Conselho Nacional de Educação. Resolução № 2, de 15 de junho de 2012. Estabelece as Diretrizes Curriculares Nacionais para a Educação Ambiental. Diário Oficial da União, Brasília, 18 jun. 2012.

CARVALHO, I. C. M.; GRUM, M. Hermenêutica e educação. In: FERRARO JUNIOR, L. A. Encontros e Caminhos: Formação de educadoras(es) ambientais e coletivos educadores. Brasília: MMA, Diretoria de Educação Ambiental, 2005.

CHAER, G.; DINIZ, R. R. P.; RIBEIRO, E. A. A técnica do questionário na pesquisa educacional. Evidência, Araxá-MG, v. 7, n. 7, p. 251-266, 2011.

DIAS, G. F. Atividades interdisciplinares de Educação Ambiental. 2 ed. São Paulo: Gaia, 2006.

DURKHEIM, É. Sociologia e filosofia. São Paulo: Martin Claret, 2009.

FAGGIONATO, S. Percepção ambiental. 2002. Disponível em: $<$ http://ambientes.ambientebrasil.com.br/educacao/artigos/percepcao_ambienta I.html>. Acesso em: 29 ago. 2016.

FREITAS, M. R. Conservação e percepção ambiental por meio da triangulação de métodos de pesquisa. 2009. 99 f. Dissertação (Mestrado em Manejo Ambiental) - Universidade Federal de Lavras. Lavras - MG: 2009.

FREITAS, M. R.; MACEDO, R. L. G.; FERREIRA, E. B.; BUSCARIOLI, G. N. R. Da teoria à ação: materiais didáticos em percepção ambiental. Revista Educação Ambiental em Ação, Número 30, Ano VIII, Dez./2009-Fev./2010, Novo Hamburgo - RS.

GERHARDT, T. E.; SILVEIRA, D. T. (Org.) Métodos de pesquisa. Porto Alegre: Editora da UFRGS, 2009.

GIL, A. C. Métodos e técnicas de pesquisa social. 5. ed. São Paulo: Atlas, 1999.

GIL, A. C. Como classificar as pesquisas. São Paulo: Atlas, 2002.

MACHADO, L. M. C. P. A percepção do meio ambiente como suporte para a Educação Ambiental. In: POMPÊO, M. L. M. (ed.) Perspectivas da Limnologia no Brasil. São Luís: Gráfica e Editora União, 1999.

MATTOS, E.; MENEGAZZO, R. F.; PILATI, R. Percepção ambiental através da representação fotográfica, ferramenta de sensibilização para questões ecológicas. In: VIII Simpósio de Ciências Biológicas. Anais... Cascavel: Universidade Paranaense (UNIPAR), 2008.

PHILIPPI, A.; PELICIONE, M. C. F. Educação Ambiental e Sustentabilidade. São Paulo: Ed Manole, 2005. 
RAZZOLINI, M. T. P.; GÜNTHER, W. M. R. Impactos na saúde das deficiências de acesso a água. Saúde e Sociedade, São Paulo, v. 17, n.1, p.21-32, 2008.

REIGOTA, M. Meio ambiente e representação social. São Paulo: Cortez, 1995.

RODRIGUES, M. L.; MALHEIROS, T. F.; FERNANDES, V.; DARÓS, T. D. A percepção ambiental como instrumento de apoio na gestão e na formulação de políticas públicas ambientais. Saúde Soc., São Paulo, v.21, supl.3, p.96-110, 2012.

SATO, M. Educação para o ambiente amazônico. 1997. 245 f. Tese (Doutorado em Ecologia e Recursos Naturais) - Universidade Federal de São Carlos. São Carlos - SP: 1997.

SATO, M. Educação Ambiental. São Carlos: Rima, 2002.

SILVA, A. L. $O$ engajamento e o desempenho organizacional a partir da relação entre valores pessoais e organizacionais: um estudo de caso do Colégio Marista Assunção. 2012. Disponível em:<https://www.lume.ufrgs.br /bitstream/handle/10183/83501/000906641.pdf?sequence=1>. Acesso em: 02 set. 2016.

SILVA, M. M. P.; LEITE, V. D. Estratégias para realização de Educação Ambiental em escolas do ensino fundamental. Revista Eletrônica do Mestrado em Educação Ambiental, Porto Alegre, v. 20, jan./jun., p. 372-392, 2008.

SMYTH, J. C. Environment and education: a view of a changing scene. Environmental Education Research, Abington, n. 1, v. 1, Feb./1995, p. 3-20.

TALAMONI, J. L. B.; SAMPAIO, A. C. (Org.) Educação Ambiental: da prática pedagógica à cidadania. São Paulo: Escrituras Editora, 2003. 